\title{
Análise dos Determinantes dos custos de resíduos sólidos urbanos nas capitais estaduais brasileiras
}

\author{
Analysis of urban solid waste costs determinants in Brazilian state capitals
}

Waldecy Rodrigues ${ }^{[a]}$, Luiz Norberto Lacerda Magalhães Filho ${ }^{[b]}$, Regiane dos Santos Pereira ${ }^{[0]}$

[a] Universidade do Federal do Tocantins (UFT), Palmas, TO, Brasil

[b] Instituto Federal de Educação Ciência e Tecnologia do Tocantins (IFTO), Dianópolis, TO, Brasil

\section{Resumo}

Este artigo tem como principal objetivo fazer uma análise e discussão dos fatores que influenciam de forma direta nos custos per capita dos resíduos sólidos urbanos nas capitais brasileiras. Foram levantados dados sobre os custos com resíduos sólidos e especificado um modelo econométrico multivariado para compreender seus determinantes. Conclui-se que os custos com resíduos sólidos dependem da forma de manejo escolhida (existência da coleta seletiva), mas são fortemente influenciados pela forma de gestão assumida pelo município. Diferente, do que a literatura microeconômica neoclássica prega, no caso dos resíduos sólidos, nas capitais brasileiras, a existência do setor privado na operação dos serviços tende a trazer pressões de aumento dos custos dos serviços oferecidos maiores que quando operados pelo poder público ou de forma mista.

Palavras-chave: Resíduos sólidos urbanos. Custos da limpeza urbana. Coleta de lixo.

\section{Abstract}

This article aims to analyze and discuss factors that directly influence the per capita cost of urban solid waste in the Brazilian capitals. Information was collected on the costs of solid waste and specified a multivariate econometric model to understand its determinants. It was concluded that the waste costs depend on the management method elected (existence of selective collection), but are strongly influenced by the municipality management. Contrary to what the neoclassical microeconomic literature says, in the case of solid waste, in Brazilians capitals, the existence of the private sector in the service operation tends to bring increased pressure from higher services costs offered when operated by the government or mixed form.

Keywords: Solid waste. Costs of urban cleaning. Waste collection.

WR é economista, pós-doutor em Ciências Sociais Aplicadas pela Universidade de Brasília (UnB), professor adjunto da Universidade do Federal do Tocantins (UFT), e-mail: waldecy@terra.com.br

LNLMF é engenheiro ambiental, mestre em Engenharia Ambiental pela Universidade Federal do Tocantins (UFT), professor do Instituto Federal de Educação Ciência e Tecnologia do Tocantins (IFTO), e-mail: luiznorberto.filho@ifto.edu.br RSP é economista, graduada pela Universidade Federal do Tocantins (UFT), e-mail: regianeuft@uol.com.br 


\section{Introdução}

O problema da geração, composição e destinação de resíduos sólidos urbanos (RSU) é de abrangência internacional, afetando, de forma distinta, tanto países desenvolvidos, em desenvolvimento e pobres. De forma geral, este processo é relacionado com o modo de vida e com as condições socioeconômicas da população, onde tem se tornado cada vez mais fácil à sua acessibilidade aos bens de consumo. 0 total mundial de resíduos sólidos produtos da população urbana é de 1,3 bilhões de toneladas por ano, ou $1,2 \mathrm{~kg}$ por dia para cada habitante em área urbana. Cerca de metade são produzidos nos países da OCDE (Organização para a Cooperação e o Desenvolvimento Econômico, que inclui os 34 países mais ricos do mundo). As previsões são que o valor total vá crescer para 2,2 bilhões de toneladas em 2025, somente com a China vai aumentar três vezes a sua quantidade (de 520 milhões de toneladas para 1,4 bilhões) (Hoornweg \& Bhada-Tata, 2012).

Os países da OCDE geram 2,2 kg per capita, em média, por cada cidadão em um único dia. Contrastando com a África, que gera $0,65 \mathrm{~kg} / \mathrm{hab}$./dia, enquanto os países da América Latina e do Leste Asiático (incluindo China) geram em média 1,11 kg/hab./dia. Nos países da OCDE $100 \%$ dos resíduos tem destinação com algum manejo, sendo $22 \%$ destinados para a reciclagem. Enquanto nos países da África, apenas 9\% dos resíduos tem destinação adequada (Hoornweg \& Bhada-Tata, 2012).

No Brasil, um país de renda per capita intermediária, é gerado diariamente $1,23 \mathrm{~kg} / \mathrm{hab}$./dia. 0 destino final dos resíduos sólidos nos municípios brasileiros ainda apresentam dados preocupantes, pois $28,4 \%$ desses municípios ainda destinam esses resíduos a céu aberto, apesar de ter diminuído ao longo dos últimos dez anos. Cerca de $39,8 \%$ os resíduos brasileiros são direcionados a aterros sanitários e, em 31,8\% dos municípios, os resíduos são destinados a aterros controlados. Apenas $18 \%$ dos municípios brasileiros possuem programas oficiais de coleta seletiva, e somente $0,7 \%$ dos metais reciclados são coletados por programas oficiais de coleta seletiva, para os plásticos, esse número sobe para $17.7 \%$, e quanto aos resíduos orgânicos, 1,6\% deles são encaminhados para compostagem (IPEA, 2012; ABRELPE, 2012).

De acordo com D'Almeida (2000), sabe-se que o poder público é o órgão responsável pelo funcionamento dos serviços de limpeza urbana e, por isso cada município deve obter um modelo de gestão próprio e que seja compatível com a realidade do local. A execução desse serviço pode ser realizada diretamente pelo município ou através de terceiros, por meio de licitação e contrato de prestação de serviços. Os preços e custos dos sistemas de limpeza pública distinguem-se nas diversas regiões do Brasil, de forma que a quantidades de resíduo coletado e as características também influenciam esses valores.

Como estão estes custos hoje nas capitais brasileiras? Quais são as variáveis determinantes no dimensionamento do custo de resíduos sólidos urbanos nas capitais brasileiras? Será que a forma de gestão do serviço de manejo de resíduos sólidos, se público ou terceirizado, influenciam os custos? São questões a serem desenvolvidas no presente trabalho.

Este artigo tem como objetivo principal analisar as variáveis determinantes do custo de resíduos sólidos urbanos nas capitais brasileiras. Para isto, serão descritas as formas de gestão de prestação de serviços de resíduos sólidos urbanos nas capitais brasileiras e sua influência nos custos per capita de coleta, manejo e destinação dos resíduos sólidos. Também, serão verificados os efeitos do tamanho da população e da densidade urbana nos custos dos resíduos sólidos urbanos das capitais brasileiras. Por fim, será analisado como a presença de coleta seletiva nas capitais brasileiras influencia nos custos dos resíduos sólidos urbanos.

\section{Determinantes dos custos de resíduos sólidos urbanos}

Custos de resíduos sólidos urbanos

e morfologia das cidades

Para Lamas (2000), morfologia das cidades é um conceito relacionado aos aspectos visíveis, externos do ambiente urbano (monumentos, praças, ruas, cheios e vazios) individualizados como elementos, porém componente intrínseco das relações que definem e explicam a paisagem urbana. Sendo a forma dos espaços urbanos variável no tempo e no espaço. Para Ferrari (1991), a forma de uma cidade influi em seu sistema de tráfego, na implantação dos equipamentos urbanos, nos custos de urbanização, 
além de exercer influência na vida socioeconômica do grupo social.

Assim sendo, as formas físicas que a cidade assume, além de depender do meio físico em que se implantou, sofrem as influências de seu sistema de tráfego, de seus equipamentos urbanos e do convívio social das pessoas, entre outros. Portanto, a forma urbana será um elemento da cidade como um ser social, e conhecer a cidade como ambiente de relações sociais implica identificar os elementos morfológicos na cidade, de forma a conhecer as partes de sua forma e o modo como estruturam no espaço urbano.

O dimensionamento dos custos de resíduos sólidos urbanos tem uma elevada dependência com a morfologia das cidades, com seu traçado, a densidade demográfica presente, e o tipo de serviço almejado pela população. Além disso, pode-se dizer que os hábitos culturais da população podem afetar estes custos, como por exemplo, onde existe maior nível de engajamento e solidariedade entre os moradores com a sustentabilidade espera-se um custo menor com a limpeza, e uma maior facilidade para se implantar programas de coleta seletiva, por exemplo.

Fonseca (2006) afirma que os serviços de limpeza urbana exigem frequência e periodicidade bem definidas e no qual a confiabilidade da população em sua execução é de fundamental importância. Para efeito de melhor análise dos custos ou preços praticados pela coleta e transporte dos resíduos sólidos regularmente descartados pela população de uma cidade há a necessidade de possuir esclarecimentos de vários aspectos, como:

- se a atividade é realizada somente pela municipalidade, por empresa contratada ou tanto pela municipalidade quanto por uma empresa;

- os salários praticados na região referentes às diferentes funções existentes (coletores, motoristas, mecânicos, encarregados e outros);

- a quantidade de ajudantes gerais (coletores) utilizados nos veículos de coleta;

- a frequência (diária, alternada ou periódica) e a periodicidade utilizada nos serviços (diurna, noturna ou diurna e noturna);

- operação e manutenção dos veículos, combustível, pneus, lubrificação, impostos (IPVA), seguros, licenciamento, remuneração e depreciação do investimento, e demais equipamentos utilizados, tais como os contêineres;
- uniformes e equipamentos de segurança individuais (EPI's).

\section{Custos de resíduos sólidos urbanos e estrutura de mercado}

As estruturas de mercado afetam diretamente os preços dos bens e serviços, inclusive os chamados bens ou serviços públicos, como é caso da limpeza urbana e a coleta e tratamento de resíduos sólidos. As estruturas de mercado geram distintas configurações entre oferta e demanda, onde os preços são determinados pelo poder de mercado das firmas, sua interdependência e condições de maximização de lucros. 0 governo através de políticas reguladoras é um agente que pode agir no sentido de interferir no processo de determinação de preços pelas firmas, porém as forças de mercado são sempre um vetor presente.

As estruturas de mercado são mais ou menos concentradas de acordo com poder que as firmas têm de determinação dos preços. Assim, existem formas de mercado que vão desde mercados competitivos até monopólios econômicos ou naturais. Para Pindyck \& Rubinfeld (2010), em um mercado perfeitamente competitivo, o grande número de vendedores e compradores de uma mercadoria garante que nenhum vendedor ou comprador em particular possa influenciar o preço. 0 preço é determinado pelas forças de mercado da oferta e da demanda. As empresas, individualmente, baseiam-se no preço de mercado para decidir quanto vão produzir e vender, e os consumidores também se baseiam em tal preço para decidir quanto vão adquirir. Já a concorrência monopolística é uma estrutura de mercado em que muitas empresas vendem produtos que são similares, mas não idênticos. Nesse mercado, o consumidor tem a opção de escolher entre as diversas marcas de determinado produto, pois a utilidade é a mesma, porém, o nível de satisfação que uma oferece é diferente para cada produto e o consumidor possui um fraco poder de controlar o mercado.

Pindyck \& Rubinfeld (2010), destaca também o oligopólio, em que o mercado é controlado por um número reduzido de empresas, de tal forma que cada uma tem que considerar os comportamentos e as reações das outras quando toma decisões de mercado. 0 autor reporta que o monopólio pode ocorrer por condições econômicas ou naturais. Nas condições econômicas o monopólio ocorre quando uma firma 
consegue na competição com outras, se tornar única. Já no monopólio natural, a competição não é socialmente eficiente, pois importa em elevados custos de capital, como por exemplo, as redes de distribuição de energia elétrica. Dessa forma, é preferível manter apenas uma única empresa operando naquele setor, o que justifica a manutenção do monopólio natural.

O saneamento básico é um exemplo de monopólio natural, inclusive os serviços de limpeza urbana e de coleta e tratamento de resíduos sólidos, a não ser que haja uma cidade ou região metropolitana que tenha uma divisão geográfica na prestação destes serviços com mais de uma empresa. 0 problema do monopólio natural são as falhas de mercado que pode prejudicar o fornecimento de determinados serviços essenciais à população, por isso regulá-lo é necessário. No caso de saneamento básico, a universalidade do atendimento, relacionada ao caráter essencial da prestação dos serviços, independe da capacidade de pagamento dos usuários. Dessa forma, o poder de monopólio se contrapõe ao caráter essencial dos serviços e à sua demanda inelástica, tornando a regulação fundamental para garantir o equilíbrio entre produtores e consumidores. (Galvão \& Paganini, 2009).

Galvão \& Paganini (2009) argumentam que os serviços de utilidade pública (SUPs) são alvos de um novo padrão de intervenção estatal na atividade econômica: a regulação. Portanto, sua eficiência e funcionalidade têm impacto direto sobre a sociedade. O monopólio natural é uma característica desse serviço e isso acarreta diversos problemas na relação entre o produtor e o consumidor. As transações entre ambos ficam apenas coordenadas pelo sistema de preços, podendo ocorrer falhas de mercado que afetam a alocação eficiente dos recursos na sociedade. Dentre essas falhas de mercado, pode-se destacar: externalidades, informação assimétrica ou imperfeita e poder de monopólio.

\section{Custos de resíduos sólidos urbanos e arranjos organizacionais}

0 que é mais vantajoso para a sociedade, manter a coleta e destinação de RSU sobre sua execução direta do poder publico ou encontrar modelos mistos com a participação do setor privado regulado pelo poder público. Qual será o arranjo organizacional mais eficiente na prestação desse serviço público? Uma linha argumentativa de resposta seria que depende dos custos de transação envolvidos, no entanto outros fatores devem ser levantados, conforme será discutido a seguir.

Para Coase (1937), o autor seminal da teoria dos custos transação, é necessário reconhecer que a realização de transações nas empresas (privadas ou públicas) implica em certos custos, não diretamente observáveis, derivados das formas de governança adotada pela firma. Williamson (1985) já conceitua os custos de transação como o dispêndio de recursos utilizados para planejar, adaptar e fiscalizar as interações entre os agentes econômicos, uma vez que por causa das condutas oportunistas destes (assimetria, omissão e/ou distorção de informações) há a possibilidade do surgimento de conflitos nas relações contratuais. Nota-se que uma vez que a abordagem dos custos de transação centra-se na dimensão intertemporal da coordenação em contexto de incerteza, o problema da organização econômica torna-se um problema contratual.

As formas de governança são a maneira pela qual a firma se organiza para oferecer o bem ou o serviço. Williamson (1998) classifica-as como sendo: 1) via mercado, onde o controle é menor e acontece, basicamente, em termos de preço; 2) forma híbrida (ou contratual), na qual há a existência de contratos complexos entre firmas localizadas em níveis sucessivos da cadeia produtiva; e 3) via hierárquica, baseada na propriedade total dos ativos, ou seja, a total internalização das atividades por uma única empresa. Altos custos de transação indicam que o mercado está sendo utilizado de forma ineficiente, e nesse ponto entram em cena as formas híbridas ou hierárquicas. Para Alves \& Staduto (1999), a estrutura dos custos de transação é responsável pela determinação da forma de governança (via mercado, híbrida ou hierárquica), provendo maior ou menor eficiência aos bens e serviços oferecidos.

Segundo Williamson (1998), todos os contratos complexos seriam necessariamente incompletos, dado o pressuposto da racionalidade limitada. Assim, os agentes muitas vezes tomam decisões com base em informações incompletas e assimétricas em relação a seus parceiros de negócio. Para Ferreira (1999), em geral são essas assimetrias de informação que permitem o aparecimento de comportamentos oportunistas.

Ainda de acordo com Williamson (1998), as principais implicações dos pressupostos da 
racionalidade limitada, assimetria de informações e comportamentos oportunistas é que: i) contratos complexos mostram-se necessariamente incompletos; ii) a confiança entre as partes envolvidas não pode ser estabelecida simplesmente a partir da existência de um contrato, dado que todo contrato implica riscos; e iii) é possível criar-se valor adicionado com a elaboração de outras formas organizacionais que considerem a racionalidade limitada e salvaguardar as transações contra o exercício de oportunismo por parte dos agentes envolvidos. Como consequência, a organização da produção somente no mercado, também pode produzir soluções ineficientes.

Nota-se que existem alguns mecanismos para que os agentes cumpram efetivamente aquilo que contrataram com seus pares nos negócios, como o oferecimento de incentivos e prêmios por resultados melhores. No entanto, para Ferreira (1999), não se pode deixar de lado que esses mecanismos acabem tendo também um custo, o que, dependendo do caso pode ser maior do que as perdas decorrentes do comportamento oportunista. Sendo assim, os agentes devem manter um equilíbrio entre monitoramento, incentivo e comportamento oportunista.

Costa \& Araújo (2001) classificam as transações entre os agentes econômicos em três fatores: incerteza, frequência e grau de especificidade dos ativos envolvidos. A função das instituições na sociedade é reduzir a incerteza, que é própria da interação humana, estabelecendo uma estrutura estável para a sociedade. Os autores, apoiando-se em Williamson, distinguem duas formas de incerteza, uma delas é o risco: uma transação apresenta risco se existir uma probabilidade conhecida de ocorrência de um problema. A segunda é a incerteza propriamente dita, que corresponde aos distúrbios que afetam uma transação, mas que não estão associados a uma distribuição de probabilidade conhecida. A informação assimétrica e o comportamento oportunista são exemplos deste tipo de incerteza entre os agentes envolvidos na transação, que torna praticamente impossível a previsão da forma de atuação de um ou de outro.

Em relação à frequência das transações, Fagundes (1998), esclarece afirmando que só é justificada a busca por alternativas organizacionais no caso de transações efetuadas com certa regularidade, ou seja, a frequência e a duração de uma transação pode determinar o aparecimento de organizações especificamente moldadas para sua gestão e operacionalização.
Nesse sentido, na medida em que a frequência de uma dada transação aumenta maior será a vantagem em se criar uma estrutura específica para geri-la. Costa \& Araújo (2001) complementam afirmando que o aumento da frequência nas transações também traz um aumento de confiança destas, à medida que se tornam mais previsíveis.

Em suma, a pergunta central da Teoria dos Custos de Transação é: Dada a necessidade da empresa de dispor de equipamentos, insumos, etc., qual a melhor maneira de fazê-lo? Realizando uma transação de compra? (mercado) ou internalizando a produção desses fatores, ou seja, passando ela mesma a produzi-las? (hierarquia). A resposta para essas perguntas dependeria da avaliação da empresa quanto à magnitude dos custos de transação incorridos ao optar por uma ou outra dessas estruturas de governança: mercado versus hierarquia. Enfim, a hipótese básica da teoria é de que a existência de custos de transação relativamente mais elevados em transações realizadas no mercado determina a substituição desta estrutura de governança pela estrutura hierárquica da empresa como método de economizar custos de transação.

Entendido a teoria dos custos de transação, faz necessário assimilá-la sob a ótica na regulação dos serviços públicos nas suas diversas formas jurídicas das empresas que prestam esses serviços. Sabe-se que o mercado onde exista monopólio público tende a apresentar custos maiores do que o mercado que apresenta concorrência privada. Isso porque a estrutura pública é mais morosa e com menor eficiência organizacional do que a privada, ou seja, tende ter um custo de transação maior. Na estrutura pública há o pensamento de que certos equipamentos encarecem muito a instalação e também os custos operacionais. Por isso, o poder público costuma avaliar, do ponto de vista econômico, os custos do processamento dos resíduos sólidos, para orientar sua eventual utilização.

Segundo Cheibub \& Przeworski (1997), do ponto de vista teórico, agências são instituídas para combater falhas de mercado, tais como assegurar a competitividade de setores da economia, diminuir custos de transação inerentes à provisão de bens públicos, reduzir assimetrias de informação entre agentes econômicos, combater externalidades negativas advindas das interações econômicas, universalizar serviços e promover interesses dos consumidores.

Cheibub \& Przeworski (1997) argumentam que hoje, os problemas cruciais da delimitação do 
âmbito do setor público, da forma institucional da regulação pública, são em grande parte problemas de informação. Por exemplo, não tem sustentação na teoria econômica a ideia de que a privatização leva necessariamente a uma diminuição nos custos. Ao se tratar apenas da passagem de um monopólio público para privado, e na presença de informação assimétrica entre a autoridade reguladora e o monopólio privado, os potenciais ganhos de eficiência privada transformam-se apenas em lucros de monopólio. Agências reguladoras atuam sobre setores vitais da economia, assumindo diferentes estatutos jurídicos, desde sua subordinação à administração pública direta até sua existência como órgão independente.

De acordo com Madeira (2010), em algumas cidades do Brasil, as empresas de coleta de lixo pertencem ao próprio governo, mas mesmo nesse caso a regulação se faz necessária. 0 fato de o setor de saneamento básico constituir um monopólio natural não muda com a empresa pertencendo ao governo; portanto, a causa da regulação ainda está presente, pois a própria legislação brasileira, por meio da Lei 11.445 de 2007 (Brasil, 2007) impõe critérios para a regulação dos serviços de coleta e disposição de RSU. Apesar de ser esperado que a presença do governo no setor como proprietário seja suficiente para o fornecimento de um serviço de qualidade, verifica-se que em alguns casos, na ausência de um regulador independente, que os serviços são ofertados com ineficiência. A regulação terá como objetivo estabelecer padrões, garantir as metas, prevenir e reprimir o abuso econômico e definir tarifas. A entidade reguladora juntamente com a legislação vigente será responsável pelas normas técnicas, econômicas e sociais, e a concessionária deverá prover todas as informações necessárias para a avaliação do desempenho.

\section{Metodologia}

Uma das questões que o trabalho visa avaliar é quais são as característica determinantes aos custos para coleta e disposição de RSU. Para essa analise levou-se em consideração as seguintes questões: Tamanho da população, Tipo da gestão, e a existência ou não de coleta seletiva. Para tanto, foram criados três grupos de variáveis para fins analíticos:

1. Grupo por gestão: Incluem as capitais com custo per capita de resíduos sólidos urbanos por gestão, ou seja, se são monopólio público, monopólio privado, concorrência privada (concorrência entre empresas privadas sem participação do poder público) ou concorrência mista (concorrência entre empresas privadas e empresas com participação do poder público);

2. Grupo por uso ou não de coleta seletiva: Incluem as capitais com custo per capita de resíduos sólidos urbanos por existência ou não de coleta seletiva;

3. Grupo por tamanho da população: Incluem as capitais com custo per capita de resíduos sólidos por tamanho da população.

A criação desses grupos objetivou uma melhor avaliação dos dados e com isso uma melhor aplicação da metodologia proposta, o levantamento e análise das variáveis foram realizados, tendo como recorte geográfico, as vinte e seis capitais brasileiras, com exceção de Brasília, por ausência de informações na mesma base de dados.

Para a determinação das características utilizou-se a construção de modelos econométricos, pelo método da analise de regressão multivariada utilizando o programa estatístico Statistical Package for the Social Sciences - SPSS2 (versão 15.0). Com a comparação dos modelos sendo feita pelos $\mathrm{R}$ square - $\mathrm{R}^{2}$, e também de acordo com o nível de significância dos parâmetros, em que usou-se o teste " $F$ ". Para realizar todos os procedimentos referentes ao tratamento de dados e às estimações das regressões dos custos per capita dos resíduos sólidos urbanos foi especificado um modelo econométrico dos custos per capita com resíduos sólidos urbanos, conforme Equação 1:

$\operatorname{Ln}($ custos per capita RSU $)=\beta_{0}+\beta_{1} \cdot$ Pop $+\beta_{2} \cdot \operatorname{Col}+\beta_{3} \cdot$ Ges + e

Em que: "Ln" é o logaritmo para os custos per capita de RSU; "Pop" representa o tamanho da população urbana; "Col" representa a existência ou não de coleta seletiva; "Ges" representa o tipo da gestão da empresa, no setor publico ou privado (sendo essa uma variável "dummy") e $\beta$ são os coeficientes. Essas variáveis foram escolhidas por terem sido apontadas como portadoras de influência na formação dos custos per capita com resíduos sólidos urbanos.

O escopo deste estudo encontra-se voltado para a identificação do comportamento dos custos de serviços de resíduos sólidos urbanos através das variáveis escolhidas e que os influenciam, que são população, 
tipos de empresas que exploram o serviço (públicas ou privadas), formas de governança aplicadas no serviço (única ou várias empresas explorando) e o tipo de coleta realizada e sua extensão (uso ou não da coleta seletiva). Existem outras variáveis que contribuem para o custo (topografia do terreno onde ocorre a coleta, frequência de coleta, qualidade de serviço, entre outras), mas que não são estudadas, por falta de dados e/ou inadequação ao modelo econométrico construído.

\section{Resultados e discussões}

Custos com resíduos sólidos urbanos nas capitais brasileiras

A geração de RSU no Brasil apresentou um crescimento de $1,87 \%$ de 2006 para 2012, e um crescimento de $9,06 \%$ na quantidade coletada. Apesar da evolução, 6,1 milhões de toneladas de RSU deixaram de ser coletados (Gráfico 1)

Os gastos aplicados na coleta de RSU e demais serviços de limpeza urbana - coleta de lixo, varrição, destinação de resíduos e outros - são heterogêneos no Brasil, entre suas capitais. De acordo com a Tabela 1, os custos per capita são maiores nas capitais da região Sudeste ( $\mathrm{R} \$ 185,93$ em média), seguidos pelas capitais da região Norte (R $\$ 163,85$ em média), capitais do Nordeste (R $\$ 151,23$ em média), capitais do Sul (R\$125,86 em média) e capitais do Centro Oeste (R\$ 101,62 média). 0 que poderia explicar estas variações: tamanho da população, forma de gestão ou existência da coleta seletiva? Esta questão será respondida ao longo deste artigo.
Formas de gestão de resíduos

sólidos nas capitais brasileiras

O sistema de execução de serviços de limpeza pública urbana apresenta dois tipos de sistema: o de execução direta e a indireta. No sistema de execução direta, a administração pública, por meio de seus próprios órgãos: secretarias, divisões e departamentos, realiza a limpeza pública urbana, contratando servidores no regime da Consolidação das Leis Trabalhistas (CLT) ou estatutários, comprando ou alugando os equipamentos e veículos e cuidando do tratamento final dos resíduos. Este modelo de gestão é adotado pela maioria dos municípios de pequeno e médio porte no Brasil. No sistema de execução indireta, entretanto, estes serviços podem ser prestados de forma parcial ou total por uma empresa terceirizada (Fernandes, 2001).

Ainda de acordo com Fernandes (2001), ao descentralizar a execução, a administração pública designa uma pessoa jurídica com o intuito de efetuar os serviços de limpeza pública, seja por meio de uma autarquia, seja de empresa pública ou sociedade de economia mista. Caracteriza-se terceirização o fato de transferir a um terceiro a execução dos serviços. Uma prefeitura pode transferir alguns serviços ou pode também, se lhe convier, transferir integralmente o serviço de limpeza pública, o que nunca pode ocorrer é a paridade na execução destes serviços, ou seja, servidores públicos e privados executando a mesma atividade. Isto só é admissível num período de transição de um modelo para outro. Mesmo quando ocorre a terceirização total dos serviços para o setor privado, este último se responsabiliza pela execução

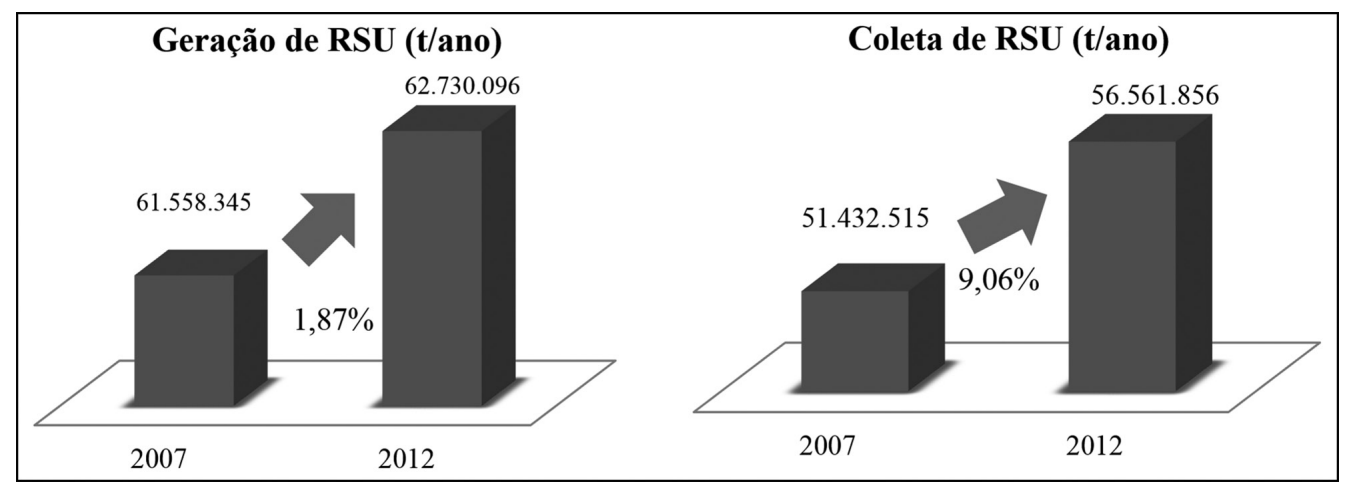

Gráfico 1 - Geração e coleta de RSU no Brasil, 2012 Fonte: ABRELPE (2012). 
Tabela 1 - Síntese dos gastos com gestão de resíduos sólidos urbanos nas capitais brasileiras, 2012

\begin{tabular}{|c|c|c|c|c|}
\hline \multirow[b]{2}{*}{ Capital } & \multirow[b]{2}{*}{ CSU Total } & \multirow{2}{*}{$\begin{array}{l}\text { CSU Per Capita Ajustado } \\
\text { (RS/hab./ano) }\end{array}$} & \multicolumn{2}{|c|}{ Custos Per Capita do serviço em relação ao CSU tota } \\
\hline & & & Coleta de lixo & $\begin{array}{l}\text { Varrição, Destinacçõo de } \\
\text { Residuos e outros }\end{array}$ \\
\hline Aracaju & 86.064 .825 & 169,22 & 55,63 & 113,59 \\
\hline Fortaleza & 217.227.072 & 142,43 & 46,83 & 95,60 \\
\hline João Pessoa & 49.903 .836 & 134,98 & 44,38 & 90,60 \\
\hline Maceió & 68.001 .629 & 141,22 & 46,76 & 95,47 \\
\hline Natal & 131.688 .653 & 184,00 & 60,49 & 123,50 \\
\hline Recife & 185.899.197 & 158,18 & 52,00 & 106,18 \\
\hline Salvador & 294.103 .036 & 143,86 & 47,30 & 96,56 \\
\hline São Luís & 113.423 .208 & 154,83 & 50,90 & 103,93 \\
\hline Teresina & 51.734 .083 & 131,40 & 43,20 & 88,20 \\
\hline Belém & 152.628 .238 & 166,87 & 63,98 & 102,89 \\
\hline Boa Vista & 37.168 .697 & 184,47 & 70,73 & 113,74 \\
\hline Macapá & 17.501 .556 & 131,77 & 50,52 & 81,24 \\
\hline Manaus & 148.488 .486 & 135,99 & 52,14 & 83,85 \\
\hline Palmas & 26.771 .561 & 182,35 & 69,92 & 112,43 \\
\hline Porto Velho & 46.771 .139 & 180,79 & 69,32 & 111,47 \\
\hline Rio Branco & 30.948 .868 & 164,70 & 63,15 & 101,55 \\
\hline Belo Horizonte & 152.481 .078 & 152,64 & 55,92 & 96,72 \\
\hline Rio de Janeiro & 602.476 .031 & 186,57 & 68,35 & 118,22 \\
\hline São Paulo & 1.384 .615 .938 & 190,80 & 69,90 & 120,90 \\
\hline Vitória & 64.575 .812 & 213,70 & 78,29 & 135,41 \\
\hline Campo Grande & 77.092 .904 & 106,05 & 49,65 & 56,40 \\
\hline Cuiabá & 55.283 .052 & 113,96 & 53,35 & 60,61 \\
\hline Goiânia & 68.816 .819 & 84,84 & 39,72 & 45,12 \\
\hline Curitiba & 127.126 .995 & 129,31 & 57,90 & 71,40 \\
\hline Florianópolis & 70.357 .470 & 144,82 & 64,85 & 79,97 \\
\hline Porto Alegre & 70.477 .406 & 103,44 & 46,32 & 57,12 \\
\hline
\end{tabular}

Fonte: Elaboração própria a partii de Brasil (2013).

e gerenciamento, mas fica a cargo da administração pública a fiscalização e a regulamentação dos serviços.

A contratação mediante concessão de serviço público é o modelo adequado à terceirização quando existe a necessidade de investimentos, como compra de caminhões apropriados à coleta dos resíduos ou construção de aterro sanitário, ou ainda quando se pretende a terceirização integral do processo de coleta e tratamento dos resíduos e não somente uma ou alguma de suas etapas (Fernandes, 2001).
A Tabela 2 a seguir apresenta a participação dos setores públicos e privados na gestão de resíduos sólidos urbanos em 2012, assim como o tipo de concorrência nas capitais brasileiras. As formas de execução dos serviços de coleta de resíduos sólidos urbanos, ou seja, a natureza das empresas (se pública ou privada) juntamente com o tipo de concorrência (se privada ou mista) e se possui monopólio privado, monopólio público, concorrência privada ou concorrência mista. 
Tabela 2 - Participaç̃ão dos setores públicos e privados na gestão de resíduos sólidos urbanos nas capitais brasileiras, 2012

\begin{tabular}{|c|c|c|c|c|}
\hline Capital & Monopólio público & Monopólio privado & Concorrência privada & Concorrência mista \\
\hline Aracaju & & & & $x$ \\
\hline Belém & & & & $x$ \\
\hline Belo Horizonte & $x$ & & & \\
\hline Boa Vista & & & $x$ & \\
\hline Campo Grande & & & $x$ & \\
\hline Cuiabá & $x$ & & & \\
\hline Curitiba & & & $x$ & \\
\hline Florianópolis & & & & $x$ \\
\hline Fortaleza & & & $x$ & \\
\hline Goiânia & $x$ & & & \\
\hline João Pessoa & & & $x$ & \\
\hline Macapá & & $x$ & & \\
\hline Maceió & & $x$ & & \\
\hline Manaus & & & $x$ & \\
\hline Natal & & & $x$ & \\
\hline Palmas & & $x$ & & \\
\hline Porto Alegre & & & $x$ & \\
\hline Porto Velho & & & $x$ & \\
\hline Recife & & & $x$ & \\
\hline Rio Branco & & $x$ & & \\
\hline Rio de Janeiro & $x$ & & & \\
\hline Salvador & & & $x$ & \\
\hline São Luís & & & & $x$ \\
\hline São Paulo & & & $x$ & \\
\hline Teresina & & $x$ & & \\
\hline Vitória & & $X$ & & \\
\hline
\end{tabular}

Fonte: Elaboração própria a partir de IBGE (2012).

Constata-se que há uma tendência à privatização dos serviços de resíduos sólidos urbanos nas capitais brasileiras. A maioria das capitais apresentadas no quadro acima possui maior participação do setor privado na execução dos serviços. Na Tabela 2 destacam-se as capitais: Boa Vista, Campo Grande, Curitiba, Fortaleza, João Pessoa, Manaus, Natal, Porto Alegre, Porto Velho, Recife, Salvador e São Paulo, onde a tendência de grande parte dos serviços é administrada pelo setor privado na execução dos serviços de resíduos. Já as capitais, Aracaju, Belém, Florianópolis e São Luís apresentaram a presença de concorrência mista em seus serviços de resíduos. Apenas quatro capitais que possuem monopólio público são Belo Horizonte, Cuiabá, Goiânia e Rio de Janeiro. Seis capitais possuem monopólio privado: Macapá, Maceió, Palmas, Rio Branco, Teresina e Vitória.

Análise dos determinantes dos custos per capita de resíduos sólidos urbanos nas capitais brasileiras

Através de um modelo econométrico multivariado, foram verificadas quais variáveis (população, coleta seletiva e formas de gestão do serviço) são mais 
impactantes nos custos per capita com resíduos sólidos nas capitais brasileiras. Assim foi especificado e estimado o modelo econométrico disposto na Tabela 3, a seguir.

Neste modelo econométrico observa-se que os coeficientes de inclinação são estatisticamente significativos e apresentaram os sinais esperados, uma vez que para os coeficientes da variável população, coleta seletiva e forma de gestão apresentaram sinais positivos.

Primeiramente, evidencia-se uma correlação positiva entre o tamanho da população e os custos per capita de resíduos sólidos urbanos, de acordo com o Gráfico 2, ao contrário do esperado, que o custo per capita reduza na medida em que a população fosse maior, em virtude das forças de economia de escala.

Conforme evidencia-se no Gráfico 3, para a variável "coleta seletiva", o sinal positivo demonstra que nas capitais brasileiras existe um custo per capita maior para as capitais que possuem coleta seletiva. Isto é naturalmente esperado, uma vez que a coleta seletiva tem um custo maior na sua execução.

No caso das formas de gestão, observaram-se sinais positivos para as variáveis dummy (variável explicativa que assume apenas dois valores: a presença (1) ou ausência (0) de um atributo) "monopólio público" e "concorrência privada". Indicando para um maior impacto da concorrência privada sobre os custos per capita

Tabela 3 - Modelo logaritmo natural de custos per capita de resíduos sólidos urbanos das capitais brasileiras para 0 ano de 2012

\begin{tabular}{lcc}
\hline \multicolumn{1}{c}{ Variável } & Capitais & \\
\hline & Coef. $^{1}$ & P-Valor \\
População urbana & 0,013960543 & 0,127209202 \\
& $(0,008807242)$ & \\
Monopólio público & 76,07539084 & 0,175822368 \\
& $(54,38738877)$ & \\
Concorrência privada & 97,91256423 & 0,010500959 \\
& $(35,00316933)$ & \\
Coleta Seletiva & 86,65964927 & 0,026582329 \\
& $(36,4592504)$ & \\
Teste F & $5,21797 \mathrm{E}-05$ & \\
P-valor Estatística F & 11,1457584 & \\
R2 $^{2}$ & 0,669585496 & \\
\hline
\end{tabular}

'Erro padrão entre parênteses.

Fonte: Elaboração própria a partir dos dados do IBGE (2013). com resíduos sólidos. Ou seja, nas capitais brasileiras a execução direta pelo poder público tem um menor custo per capita que os arranjos terceirizados. 0 pior resultado é quando há uma situação de monopólio privado, ou seja, a licitação concedida a somente uma empresa executora (Gráfico 4).

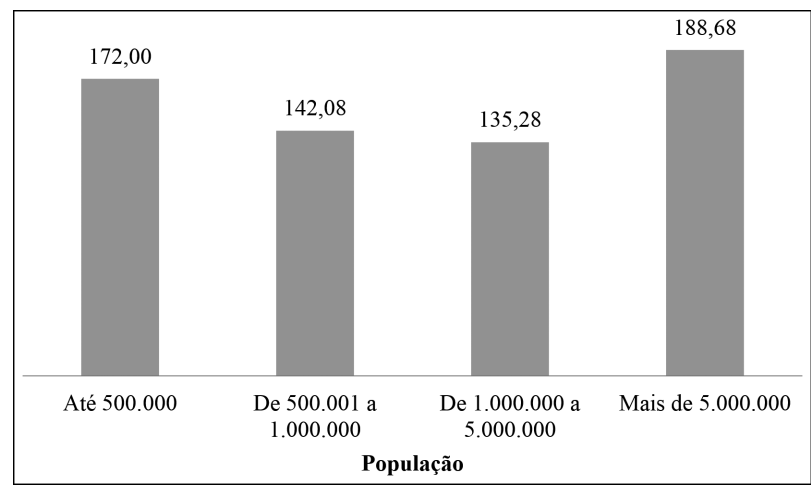

Gráfico 2 - Relação entre custos de resíduos sólidos urbanos e o tamanho da população

Fonte: Elaboração própria a partir de IBGE (2013).

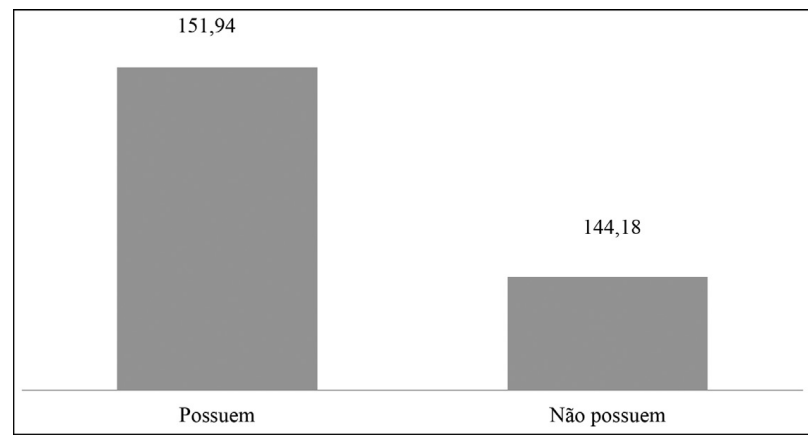

Gráfico 3 - Relaccão entre os custos de resíduos sólidos urbanos e existêncio ou não de coleta seletiva

Fonte: Elaboração própria a partir de IBGE (2013).

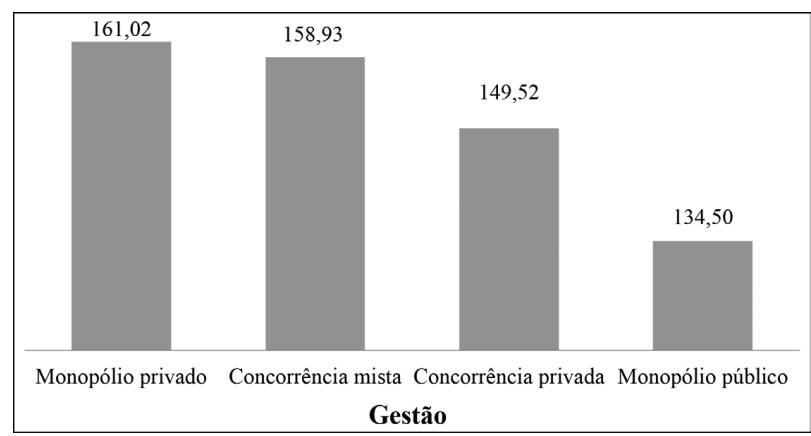

Gráfico 4 - Relação entre os custos de resíduos sólidos urbanos e gestão das empresas

Fonte: Elaboração própria a partir de IBGE (2013). 


\section{Conclusão}

Este trabalho conclui que os custos com resíduos sólidos dependem da forma de manejo escolhida (existência da coleta seletiva), mas fundamentalmente da forma de gestão assumida pelo município. Diferente, do que a literatura microeconômica neoclássica propõe, no caso dos resíduos sólidos, nas capitais brasileiras, a existência do setor privado na operação dos serviços tende a trazer pressões de aumento dos custos dos serviços oferecidos, e não ao contrário, como se costuma atribuir a maior eficiência do setor privado sobre o setor público, em termos de produtividade e eficiência. 0 que naturalmente, faltaria avaliar seria a qualidade e cobertura dos serviços ofertados, não avaliados neste artigo.

Os maiores custos per capita com resíduos sólidos urbanos foram encontrados nos monopólios privados. As capitais que dispõem desta forma de oferta dos serviços públicos, apesar de realizarem licitação para estas empresas, no final apresentaram custos maiores. O monopólio público apresentou custos menores, o que demonstra que o procedimento de concessão ao setor privado vem gerando custos per capita maiores.

Outro ponto importante, é que nas capitais onde se tem modelos mistos, ou seja, a presença de mais de uma empresa prestando o serviço, os custos tende a ser menores que no caso do monopólio privado. 0 que leva a deduzir, que o poder público, que não deseja ou pode manter uma estrutura própria, deve estimular a concorrência não só na licitação, mas também na execução dos serviços.

\section{Referências}

Alves, J. M., \& Staduto, J. A. R. (1999). Análise da estrutura de governança: o caso cédula do produtor rural (CPR). In Anais do II Workshop Brasileiro de Gestão de Sistemas Agroalimentares (p. 137-147). Ribeirão Preto: FEA/USP.

Associação Brasileira de Empresas de Limpeza Pública e Resíduos Especiais - ABRELPE. (2012). Panorama dos resíduos sólidos no Brasil. (10a ed.). São Paulo: ABRELPE. Recuperado em 20 de abril de 2015, de http://www. abrelpe.org.br/panorama_apresentacao.cfm.

Brasil. (2005). Lei n. 11.445, de 5 de janeiro de 2007. Estabelece as diretrizes nacionais para o saneamento básico. Brasília: Diário oficial [da] Republica Federativa do Brasil.
Brasil. Ministério da Fazenda. Tesouro Nacional. (2013). Finbra: finanças do Brasil. Brasília: Ministério da Fazenda. Recuperado em 26 de outubro de 2015, de http://www. tesouro.fazenda.gov.br/pt_PT/finbra-financas-municipais

Cheibub, J. A., \& Przeworski, A. (1997). Democracia, eleições e responsabilidade política. Revista Brasileira de Ciencias Sociais, 12(35). http://dx.doi.org/10.1590/ S0102-69091997000300004

Coase, R. H. (1937). The nature of the firm. Economica. New Series, 4(16), 386-405. http://dx.doi.org/10.1111/j.1468-0335.1937. tb00002.x

Costa, L. C., \& Araújo, M. P. (2001). Integração vertical na agroindústria avícola: busca de evidência empírica para a teoria dos custos de transação. In Anais do XXXIX Congresso Brasileiro de Economia e Sociologia Rural (p.110). Recife: SOBER.

D’Almeida, M. L. O. (2000). Lixo municipal: manual de gerenciamento integrado (2a ed.). São Paulo: IPT/CEMPRE.

Fagundes, J. (1998). Economia institucional: custos de transação e impactos sobre política de defesa da concorrência. Revista de Economia Contemporânea, 2, 1-44. Recuperado em 20 de abril de 2015, de http://www.ie.ufrj.br/grc/ pdfs/custos_de_transacao_e_impactos_sobre_politica_de_ defesa_da_concorrencia.pdf.

Fernandes, J. U. J. (2001). Lixo - limpeza pública urbana - gestão de resíduos sólidos sob o enfoque do direito administrativo. Belo Horizonte: Del Rey.

Ferrari, C. (1991). Curso de planejamento municipal integrado (7a. ed.). São Paulo: Pioneira.

Ferreira, C. F. (1999). Crescimento econômico na presença de custos de transação. In Anais IV SEMEAD (p. 1-9). São Paulo: FEA -USP. Recuperado em 20 de abril de 2015, de http://www.ead.fea.usp.br/semead/4semead/artigos/ pnee/ferreira.pdf

Fonseca, A. M. (2006). Metodologia para auditoria de serviços de limpeza urbana, com enfoque nos custos de coleta de resíduos sólidos urbanos. Curitiba: TCE.

Galvão, A. C., Jr., \& Paganini, W. S. (2009). Aspectos conceituais da regulação dos serviços de água e esgoto no Brasil. Engenharia Sanitária e Ambiental, 14(1), 79-88.

Hoornweg, D., \& Bhada-Tata, P. (2012). What a waste: a global review of solid waste management. Washington: World Bank. Recuperado em 20 de abril de 2015, de https:// openknowledge.worldbank.org/handle/10986/17388. 
Instituto Brasileiro de Geografia e Estatística - IBGE. (2012). IBGE cidades. Rio de Janeiro: IBGE. Recuperado em 20 de abril de 2015, de http://www.ibge.gov.br.

Instituto de Pesquisa Econômica Aplicada - IPEA (2012). Diagnóstico dos resíduos sólidos urbanos - Relatório de pesquisa. Brasília: IPEA.

Lamas, J. M. R. G. (2000). Morfologia urbana e desenho da cidade (2a ed.). Lisboa: Fundação Calouste Gulbenkian.

Madeira, R. F. (2010). O setor de saneamento básico no Brasil e as implicações do novo marco regulatório para a universalização do acesso. Revista do BNDES, 33, 123-154.
Pindyck, R., \& Rubinfeld, D. L. (2010). Microeconomia (7a ed.). Rio de Janeiro: Prentice Hall.

Williamson, O. E. (1985). The economic institutions of capitalism: firms, markets, relational contracting (10a ed.). New York: The Free Press.

Williamson, O. E. (1998). Transaction cost economics: how it works. De economist, 146(1), 23-58. http://dx.doi. org/10.1023/A:1003263908567

Recebido: Jan. 24, 2015

Aprovado: Jun. 15, 2015 